\title{
Comparisons of commuter's exposure to particulate matters while using different transportation modes
}

\author{
Dai-Hua Tsai, Yi-Her Wu, Chang-Chuan Chan* \\ Institute of Occupational Medicine and Industrial Hygiene, College of Public Health, National Taiwan University, Taiwan
}

\section{A R T I C L E I N F O}

Article history:

Received 11 March 2008

Received in revised form

11 June 2008

Accepted 12 June 2008

Available online 26 July 2008

Keywords:

Particulate matter (PM)

Commuter exposure

Transportation mode

\begin{abstract}
A B S T R A C T
This study compared commuters' exposures to particulate matter (PM) while using motorcycles, cars, buses, and the mass rapid transit (MRT) on the same routes in Taipei, Taiwan. Motorcycle commuters who had the shortest travel time $(28.4 \pm 4.2 \mathrm{~min})$ were exposed to the highest concentrations of $\mathrm{PM}_{10}\left(112.8 \pm 38.3 \mu \mathrm{g} / \mathrm{m}^{3}\right), \mathrm{PM}_{2.5}\left(67.5 \pm 31.3 \mu \mathrm{g} / \mathrm{m}^{3}\right)$, and $\mathrm{PM}_{1.0}\left(48.4 \pm 24.7 \mu \mathrm{g} / \mathrm{m}^{3}\right)$ among four commuting modes. By contrast, car commuters were exposed to the lowest PM concentrations and had the second shortest travel time among them. Motorcycle commuters' high trip-averaged PM concentrations and bus commuters' long commuting time $(43.1 \pm 5.1 \mathrm{~min})$ resulted in their high whole-trip PM exposures. Size fractions of PM were relatively consistent across PM exposures of the four commuting modes with fine particles $\left(\mathrm{PM}_{2.5}\right)$ contributing to $53-60 \%$ of $\mathrm{PM}_{10}$ and submicron particle $\left(\mathrm{PM}_{1}\right)$ contributing to $39-43 \%$ of $\mathrm{PM}_{10}$. Motorcycles idled at traffic lights and bus doors opened at stops increased commuters' PM exposures. Fixed-site monitoring data explained well the variation of whole-trip $\mathrm{PM}_{10}$ exposure of car $\left(r^{2}=0.63\right)$ and MRT $\left(r^{2}=0.52\right)$ commuters, and of whole-trip $\mathrm{PM}_{2.5}$ exposure of car $\left(r^{2}=0.76\right)$, MRT $\left(r^{2}=0.73\right)$ and motorcycle $\left(r^{2}=0.64\right)$ commuters in regression analyses. The coefficients (slopes) of regression between fixed-site monitoring data and $\mathrm{PM}_{2.5}$ exposures were less than 1 for car and MRT commuters but greater than 1 for motorcycle commuters. In conclusion, proximity to traffic emissions contributes to a person's high PM exposure during his or her daily commute. This proximity occurs when people use motorcycles on roads and when bus/MRT commuters walk or wait along commuting routes. Fixed-site air monitoring data can under-estimate motorcycle commuters' $\mathrm{PM}_{2.5}$ exposures but over-estimate car and MRT commuters' $\mathrm{PM}_{2.5}$ exposures.
\end{abstract}

(c) 2008 Elsevier B.V. All rights reserved.

\section{Introduction}

The epidemiological association between exposure to air pollution and cardiovascular morbidity and mortality has been well documented in previous studies (Dominici et al., 2006; Pope et al., 2004; Pope and Dockery, 1999). Many studies have documented significant cardiovascular effects by coarse particles with diameters less than $10 \mu \mathrm{m}\left(\mathrm{PM}_{10}\right)$, and fine particles with diameters less than $2.5 \mu \mathrm{m}\left(\mathrm{PM}_{2.5}\right)$ (Chuang et al.,
2007; Samet et al., 2000). Recent studies also reported that either submicrometer particles with size less than $1 \mu \mathrm{m}$ in diameter $\left(\mathrm{PM}_{1.0}\right)$ or ultrafine particles (less than $0.1 \mu \mathrm{m}$ ) increase the cardiorespiratory symptoms and decrease the heart rate variability for elderly patients (Chan et al., 2004; Chuang et al., 2005; de Hartog et al., 2003).

Both $\mathrm{PM}_{10}$ and $\mathrm{PM}_{2.5}$ are known as major traffic-related air pollutants in urban environment. Specifically, traffic exposures have been reported to cause adverse health effects on

\footnotetext{
* Corresponding author. Institute of Occupational Medicine and Industrial Hygiene, College of Public Health, National Taiwan University, Rm. 722, No. 17, Xu-Zhou Rd., Taipei 100, Taiwan. Tel.: +886 2 33228082; fax: +886 223222362.

E-mail address: ccchan@ntu.edu.tw (C.-C. Chan).
} 
survivors of myocardial infraction, troopers, healthy subjects and subjects with asthma in previous studies (Peters et al., 2004; Riediker et al., 2004a; Utell et al., 1994). Several studies have investigated commuter exposure to $\mathrm{PM}_{10}$ and $\mathrm{PM}_{2.5}$ among different commuting modes, such as bicycle, bus, car, tram, subway and walking (Adams et al., 2001; Gomez-Perales et al., 2007; Gulliver and Briggs, 2004; Praml and Schierl, 2000). Only one study measured commuter exposure to $\mathrm{PM}_{1.0}$ (Chan et al., 2002a). No study on motorcyclist's PM $_{1.0}$ exposures has been published yet.

Taipei metropolitan area is a densely populated area with a population of approximately 6 million in an area of $2324 \mathrm{~km}^{2}$. In 2005, there were about 1.05 million registered motorcycles and 0.65 million registered cars. The daily average of passengers of the metro rapid train system (MRT) was about 1.05 million from 1997 to 2006, while daily bus passengers averaged at about 1.68 million in 2006 (DOT, 2006). Our previous studies on commuters' exposures to VOCs have shown significant differences between commuters using motorcycles, cars or buses as commuting modes in Taipei (Chan et al., 1993, 1994). The aims of this study were a) to evaluate commuter exposures to $\mathrm{PM}_{10}, \mathrm{PM}_{2.5}$, and $\mathrm{PM}_{1.0}$ while using four commuting modes, i.e. motorcycle, car, bus and MRT; b) to identify driving factors which may affect "invehicle" concentrations of PM, including idling periods at traffic lights, and opening of doors of vehicles; and c) to investigate the relationship between commuter exposure and measurements at the chosen fixed-site air monitoring station.

\section{Methods}

The exposure assessments during each of the commuting modes were carried out four times per day during two morning and two afternoon rush hour periods. Four commuting routes in Taipei were studied, including three routes from our commuting pattern survey in the 1990s (Chan et al., 1993, 1994) and a new one reflecting increased north-south traffic in eastern Taipei. The commuting times corresponded to those from our previous studies. On each sampling day, measurements started at 06:50, 07:30, 17:30, and 18:20. Table 1 shows the commuting distance, number of lanes, number of MRT stations, number of bus stops, number of intersection, and average hourly traffic volume during rush hours (07:00-09:00 and 17:00-19:00) on each of these routes (TEO, 2008). The characteristics of the four commuting routes were similar. The commuting distance ranged from 7.0 to $8.8 \mathrm{~km}$, and there was one MRT station every 0.9-1.1 km and one bus stop every $0.35-$
$0.44 \mathrm{~km}$ on each route. All four study routes had eight lanes with 6-12 intersections. Routes 2 and 4 had twice the number of intersections than routes 1 and 3. Traffic volumes of motorcycles were similar across four study routes. By contrast, Route 2 had much higher volumes of cars, buses and trucks than the other three routes.

Our research design required two non-smokers to take exposure measurements. We assigned commuters to start their trip at the same time according to the predetermined schedules. Each person used a different mode of travel on one of four specified routes in Taipei. For a given route and sampling day, the two trip-makers took simultaneous measurements so that exposure comparisons between travel modes could be made by maximizing the variation in the explanatory variable of travel mode and controlling the variation of daily traffic volume, which fluctuated over the hours of day and displayed double peaks in the morning and afternoon rush hours (07:00-09:00 and 17:00-19:00) (TEO, 2008).

Most Taipei city buses are powered by diesel fuel, while nearly all of the cars and motorcycles are gasoline fuelled. The MRT system uses electricity powered trains with regenerative/ rheostatic electrical braking systems (TRTC, 2005). MRT runs either underground (Routes 1, 2, and 3) or on an elevated track (Route 4). Both buses and cars in this study used air conditioning with re-circulation air mode and windows closed during the measurement periods. The underground MRT stations had centralized air-conditioning systems with filtered ambient air supply and the MRT cars used airconditioning system with air exchange mode. The designated car was a four-stroke cycle Ford TELSTAR (2000cc, 1988) and the motorcycle was a two-stroke cycle Sangyang (100cc, 1998). The driving speeds for motorcycle and car commuters were requested to be at about $30-40 \mathrm{~km} / \mathrm{h}$, in order to avoid the effects of wind speed (Alm et al., 1999).

The whole-trip exposure consists of exposure inside vehicles and outside vehicles. The time commuters spent outside vehicles includes the time between stations and the destination, and the waiting time at the bus or MRT stations. Logbooks were used by bus and MRT commuters to record time, unusual activities, and events related to exposures. It is inconvenient for motorcycle and car commuters to use logbooks while driving, therefore, video cameras were equipped for them to record their travels and unusual events, which were later identified after the trip.

Commuter's exposures to $\mathrm{PM}_{10}, \mathrm{PM}_{2.5}$, and $\mathrm{PM}_{1}$ were measured by personal samplers. Particles were measured by DUST-check Portable Dust Monitors (Model 1.108, Grimm Labortechnik Ltd., Aining, Germany) at a temporal resolution

Table 1 - Description of four sampling routes selected for the commuter exposure study in Taipei, Taiwan, 2005

\begin{tabular}{|c|c|c|c|c|c|c|c|c|}
\hline \multirow[t]{2}{*}{ Route } & \multirow{2}{*}{$\begin{array}{l}\text { Length } \\
(\mathrm{km})\end{array}$} & \multirow{2}{*}{$\begin{array}{l}\text { Lanes } \\
(\#)\end{array}$} & \multirow{2}{*}{$\begin{array}{l}\text { Intersections } \\
(\#)\end{array}$} & \multirow{2}{*}{$\begin{array}{c}\text { MRT stations } \\
(\#)\end{array}$} & \multirow{2}{*}{$\begin{array}{l}\text { Bus stops } \\
(\#)\end{array}$} & \multicolumn{3}{|c|}{ Traffic volume (vehicles/hour) } \\
\hline & & & & & & Bus and truck & Car & Motorcycle \\
\hline 1 & 7.2 & 8 & 7 & 8 & 18 & 86 & 1313 & 1330 \\
\hline 2 & 7.5 & 8 & 12 & 7 & 18 & 143 & 2036 & 1126 \\
\hline 3 & 8.8 & 8 & 6 & 8 & 20 & 93 & 1178 & 1493 \\
\hline 4 & 7.0 & 8 & 11 & 7 & 20 & 31 & 1026 & 1288 \\
\hline
\end{tabular}


of 1 min, which records $\mathrm{PM}_{10}, \mathrm{PM}_{2.5}$, and $\mathrm{PM}_{1}$ particles simultaneously. Collocated Rupprecht and Patashnick 1400a tapered element oscillating microbalance (TEOM) samplers (Thermo Electron Corporation, East Greenbush, NY, USA) have been used to calibrate the mass concentrations measured by our DUST-check monitors in a previous study (Chan et al., 2004). Concurrent PM measurements by the TEOM and the DUST-check monitor showed good association between these two monitors for three size fractions: $\mathrm{PM}_{10}(r=0.95), \mathrm{PM}_{2.5}$ $(r=0.95)$, and $\mathrm{PM}_{1.0}(r=0.87)$. All dust monitors were calibrated against reference monitors of the manufacturer prior to the study in order to ensure that their performance is comparable, i.e. the relative deviations of all measured values were all less than $2 \%$. Temperature and relative humidity were also monitored simultaneously to make sure all PM monitors function in the range of preferred environmental conditions, i.e. the temperature of $5-45^{\circ} \mathrm{C}$ and the relative humidity less than $70 \%$. In our study period, average temperature was $18.9 \pm 3.5^{\circ} \mathrm{C}$, and average relative humidity was $56.7 \pm 17.1 \%$.

In addition, we obtained ambient air pollution data provided by the Taiwan Environmental Protection Administration (TEPA) from one fixed-site monitoring station (Guting station) in downtown Taipei. Guting station is located in the center of our study area. The station was placed on the roof of a three-story building, which is $14 \mathrm{~m}$ above the ground level and $40 \mathrm{~m}$ away from main traffic roads. The fixed-site air monitoring data of $\mathrm{PM}_{10}$ and $\mathrm{PM}_{2.5}$ were used to compare with personal monitoring of commuter exposures of the same sampling periods. $\mathrm{PM}_{1.0}$ was not measured at the fixed-site station.

All descriptive computations and statistical analyses were made using SPSS software (version 11.0; SPSS Inc., Chicago, IL, USA). ANOVA with Bonferroni test at $95 \%$ significance was used to compare concentrations between different commuting modes. Independent t-tests were used to compare the concentrations inside and outside vehicles. Two-tail paired ttests were used to compare concentrations between normal operation and special events. Linear regression models were used to analyze the relationship between personal exposure concentrations and fixed-site monitoring concentrations.

\section{Results}

\subsection{Exposure comparisons between transportation modes}

The exposures of 64 whole trips were monitored on the four commuting routes from January to April 2005 in Taipei, Taiwan. The average commuting duration of each trip was $28.4 \pm 4.2 \mathrm{~min}$ by motorcycle, $30.0 \pm 4.9 \mathrm{~min}$ by car, $43.1 \pm 5.1 \mathrm{~min}$ by bus, and $33.9 \pm 8.3 \mathrm{~min}$ by MRT. As shown in Table 2, we found substantial differences in $\mathrm{PM}_{10}, \mathrm{PM}_{2.5}$ and $\mathrm{PM}_{1.0}$ concentrations among these four commuting modes $(p<0.001)$. The average concentrations of $\mathrm{PM}_{10}$ were $112.8 \mu \mathrm{g} / \mathrm{m}^{3}$ when commuting by motorcycle, $70.0 \mu \mathrm{g} / \mathrm{m}^{3}$ by bus, $64.9 \mu \mathrm{g} / \mathrm{m}^{3}$ by MRT, and $41.9 \mu \mathrm{g} / \mathrm{m}^{3}$ by car. $\mathrm{PM}_{2.5}$ and $\mathrm{PM}_{1.0}$ concentrations of motorcycle commuters were also the highest, followed by bus, MRT and car. In general, PM concentrations by motorcycle commutes were two to three times higher than other commuting modes.

We calculated the whole-trip exposure by multiplying commuting concentration and commuting time per trip, as shown in the last column of Table 2 . We found that motorcycle commuters had the highest whole-trip exposure to PM, while car commuters had the lowest. On average, motorcycle commuters had higher whole-trip PM exposure than car commuters by 2.6 to 2.9 times.

Size fractions of PM were relatively consistent across PM exposures of four commuting modes. The fine/coarse $\left(\mathrm{PM}_{2.5} /\right.$ $\mathrm{PM}_{10}$ ) ratios were 0.60 for motorcycle, 0.53 for car, 0.55 for bus, and 0.54 for MRT. The submicron/coarse $\left(\mathrm{PM}_{1.0} / \mathrm{PM}_{10}\right)$ ratios were 0.43 for motorcycle, 0.39 for car, 0.45 for bus, and 0.41 for MRT. Fine particles $\left(\mathrm{PM}_{2.5}\right)$ contributed to more than half the amount of $\mathrm{PM}_{10}$. Both fine/coarse and submicron/coarse ratios were found to be the lowest in the car mode.

The records in the logbooks and videos used by the commuters allowed us to compare pollutant concentrations inside and outside vehicles because they provided the information of the exact time when commuters entered into their vehicles. As shown in Table 3, PM concentrations inside the MRT were significantly lower than the concentrations outside the MRT.

Table 2 - Trip-averaged concentrations and whole-trip exposure (mean \pm SD) of PM by four commuting modes in Taipei, Taiwan 2005

\begin{tabular}{|c|c|c|c|c|c|}
\hline Pollutants & Commuting mode & Trip-averaged concentrations ${ }^{a}$ & $N$ (trip) & Trip duration (minutes) & Whole-trip exposures ${ }^{b}$ \\
\hline \multirow[t]{4}{*}{$\mathrm{PM}_{10}$} & Motorcycle & $112.8 \pm 38.3$ & 16 & $28.4 \pm 4.2$ & $3247 \pm 1241$ \\
\hline & Car & $41.9 \pm 14.4$ & 16 & $30.0 \pm 4.9$ & $1268 \pm 522$ \\
\hline & Bus & $70.0 \pm 22.5$ & 16 & $43.1 \pm 5.1$ & $3039 \pm 1133$ \\
\hline & MRT & $64.9 \pm 29.3$ & 16 & $33.9 \pm 8.3$ & $2138 \pm 826$ \\
\hline \multirow[t]{4}{*}{$\mathrm{PM}_{2.5}$} & Motorcycle & $67.5 \pm 31.3$ & 16 & $28.4 \pm 4.2$ & $1942 \pm 977$ \\
\hline & Car & $22.1 \pm 9.6$ & 16 & $30.0 \pm 4.9$ & $671 \pm 335$ \\
\hline & Bus & $38.5 \pm 15.6$ & 16 & $43.1 \pm 5.1$ & $1687 \pm 833$ \\
\hline & MRT & $35.0 \pm 17.4$ & 16 & $33.9 \pm 8.3$ & $1149 \pm 501$ \\
\hline \multirow[t]{4}{*}{$\mathrm{PM}_{1.0}$} & Motorcycle & $48.4 \pm 24.7$ & 16 & $28.4 \pm 4.2$ & $1388 \pm 742$ \\
\hline & Car & $16.2 \pm 6.2$ & 16 & $30.0 \pm 4.9$ & $489 \pm 219$ \\
\hline & Bus & $31.3 \pm 14.0$ & 16 & $43.1 \pm 5.1$ & $1373 \pm 752$ \\
\hline & MRT & $26.5 \pm 12.6$ & 16 & $33.9 \pm 8.3$ & $870 \pm 364$ \\
\hline
\end{tabular}

\footnotetext{
a Unit: PM concentration in $\mu \mathrm{g} / \mathrm{m}^{3}$.

b Unit: whole-trip exposure in $\mu \mathrm{g} / \mathrm{m}^{3} \mathrm{~min}$.
} 


\begin{tabular}{|c|c|c|c|c|c|c|}
\hline \multirow{2}{*}{$\begin{array}{l}\text { Commuting } \\
\text { mode }\end{array}$} & \multirow[t]{2}{*}{ Pollutants $^{a}$} & \multicolumn{2}{|c|}{ Inside vehicle } & \multicolumn{2}{|c|}{ Outside vehicle ${ }^{b}$} & \multirow[t]{2}{*}{$p$-value } \\
\hline & & $\begin{array}{c}\text { Concentration } \\
(\text { mean } \pm \mathrm{SD})\end{array}$ & $\begin{array}{l}\text { Duration } \\
\text { minutes) }\end{array}$ & $\begin{array}{c}\text { Concentration } \\
(\text { mean } \pm \mathrm{SD})\end{array}$ & $\begin{array}{c}\text { Duration } \\
\text { (minutes) }\end{array}$ & \\
\hline \multirow[t]{3}{*}{ Car } & $\mathrm{PM}_{10}$ & $41.7 \pm 15.9$ & (28.9) & $56.2 \pm 33.2$ & (1.1) & 0.092 \\
\hline & $\mathrm{PM}_{2.5}$ & $22.2 \pm 10.6$ & & $27.0 \pm 17.8$ & & 0.278 \\
\hline & $\mathrm{PM}_{1.0}$ & $16.2 \pm 7.0$ & & $19.3 \pm 11.2$ & & 0.265 \\
\hline \multirow[t]{3}{*}{ Bus } & $\mathrm{PM}_{10}$ & $69.6 \pm 35.3$ & (27.4) & $72.4 \pm 30.4$ & (15.7) & 0.284 \\
\hline & $\mathrm{PM}_{2.5}$ & $38.5 \pm 18.9$ & & $40.4 \pm 19.3$ & & 0.203 \\
\hline & $\mathrm{PM}_{1.0}$ & $31.3 \pm 17.3$ & & $32.9 \pm 16.3$ & & 0.254 \\
\hline \multirow[t]{3}{*}{ MRT } & $\mathrm{PM}_{10}$ & $46.5 \pm 23.7$ & $(14.5)$ & $75.3 \pm 46.3$ & (19.5) & $<0.001^{\circ}$ \\
\hline & $\mathrm{PM}_{2.5}$ & $28.9 \pm 14.0$ & & $37.5 \pm 23.1$ & & $<0.001^{\circ}$ \\
\hline & $\mathrm{PM}_{1.0}$ & $22.5 \pm 10.0$ & & $28.0 \pm 16.3$ & & $<0.001^{*}$ \\
\hline \multicolumn{7}{|c|}{$\begin{array}{l}\text { a Unit: PM concentration in } \mu \mathrm{g} / \mathrm{m}^{3} \text {. } \\
\text { b Outside vehicle: the time commuters spent the time from home to parking space, from home to stations, from station to destination, and the } \\
\text { waiting time at the bus or MRT stations. } \\
\text { "p-value }<0.001 \text { by using independent } t \text {-test. }\end{array}$} \\
\hline
\end{tabular}

Another significant contrast is the time commuters spent outside vehicles. Car commuters spent a majority of their times inside the vehicle (96\%), reflecting their short walking distance between their vehicles and destinations. However, bus and MRT commuters spend 36 to $57 \%$ of their commuting time outside the vehicle, respectively. The commuting time outside vehicles included the time walking from home to stations, from station to destination, and the time waiting at the bus stations. PM concentrations were all lower inside vehicles.

\subsection{Events influencing in-vehicle concentrations}

We further investigated two certain events affecting invehicle pollutant concentrations, i.e. idling of motorcyclists at traffic lights and door opening at bus stops. On average, each motorcycle trip had about 18 idling events and the duration of each event ranged from 1 to $3 \mathrm{~min}$. Bus doors were opened 9 times each trip with 1 to $3 \mathrm{~min}$ each time. We compared each idling event with an earlier driving event and each door-opening event with an earlier closed door event of the same duration, in order to determine whether the exposure increased during those events.

As shown in Table 4, motorcycle commuters idling at traffic lights had concentrations of $\mathrm{PM}_{10}, \mathrm{PM}_{2.5}$, and $\mathrm{PM}_{1.0}$ that were significantly increased by $5 \%\left(98.8\right.$ to $\left.103.9 \mu \mathrm{g} / \mathrm{m}^{3}\right), 6 \%$ (53.3 to $\left.56.7 \mu \mathrm{g} / \mathrm{m}^{3}\right)$, and $7 \%\left(36.6\right.$ to $\left.39.0 \mu \mathrm{g} / \mathrm{m}^{3}\right)$ in comparison to the levels of moving motorcycles. For bus commuters, $\mathrm{PM}_{10}$ and $\mathrm{PM}_{2.5}$ concentrations were significantly increased by $5 \%$ (from 59.8 to $62.8 \mu \mathrm{g} / \mathrm{m}^{3}$ ), and $2 \%$ (from 35.7 to $36.5 \mu \mathrm{g} / \mathrm{m}^{3}$ ) when the doors were opened compared to closed doors.

\subsection{Predicting PM concentrations while commuting by fixed-site air monitoring data}

Fig. 1 shows the relationships between $\mathrm{PM}_{10}$ and $\mathrm{PM}_{2.5}$ concentrations while commuting and corresponding concentrations measured at the fixed air monitoring station. For $\mathrm{PM}_{10}$ concentrations, better coefficients of determination $\left(r^{2}\right)$ between commuter exposure to PM concentrations and the PM concentrations measured at fixed-site monitors were seen for car $\left(r^{2}=0.63\right)$ and MRT $\left(r^{2}=0.52\right)$ commuters than for motorcycle $\left(r^{2}=0.13\right)$ and bus $\left(r^{2}=0.07\right)$ commuters. For $\mathrm{PM}_{2.5}$ concentrations, better coefficients of determination were observed for car $\left(r^{2}=0.76\right)$, MRT $\left(r^{2}=0.73\right)$ and motorcycle $\left(r^{2}=0.64\right)$ commuters than for bus $\left(r^{2}=0.28\right)$ commuters. By examining coefficients (slopes) of the regression lines between fixed-site air monitoring data and $\mathrm{PM}_{10}$ and $\mathrm{PM}_{2.5}$ exposures in Fig. 1, we found that the slopes of $\mathrm{PM}_{2.5}$ regression lines were less than 1 for car, bus and MRT commuters but greater than 1 for motorcycle commuters. In addition, we also found that the slopes of $\mathrm{PM}_{10}$ regression lines were less than 1 for car and MRT commuters.

Table 4 - Comparisons of PM concentrations while commuting between special events and normal operation for motorcycle and bus commuters in Taipei, Taiwan 2005

\begin{tabular}{|c|c|c|c|c|c|c|c|c|}
\hline \multirow[t]{3}{*}{ Pollutants ${ }^{a}$} & \multicolumn{4}{|c|}{ Motorcycle ( $N=336$ events) } & \multicolumn{4}{|c|}{ Bus ( $N=345$ events) } \\
\hline & Idling & Driving & Difference & $p$-value & Door open & Door closed & Difference & $p$-value \\
\hline & Mean \pm SD & Mean \pm SD & & & Mean \pm SD & Mean \pm SD & & \\
\hline $\mathrm{PM}_{10}$ & $103.9 \pm 45.6$ & $98.8 \pm 38.3$ & $5.0(1.2,8.8)$ & $0.009^{*}$ & $62.8 \pm 30.8$ & $59.8 \pm 28.0$ & $3.0(0.9,5.1)$ & $0.005^{*}$ \\
\hline $\mathrm{PM}_{2.5}$ & $56.7 \pm 40.1$ & $53.3 \pm 31.7$ & $3.4(0.3,6.5)$ & $0.033^{*}$ & $36.5 \pm 18.5$ & $35.7 \pm 17.9$ & $0.7(0.1,1.3)$ & $0.020^{*}$ \\
\hline $\mathrm{PM}_{1.0}$ & $39.0 \pm 30.1$ & $36.6 \pm 23.9$ & $2.4(0.1,4.7)$ & $0.045^{*}$ & $30.3 \pm 16.6$ & $29.8 \pm 16.3$ & $0.5(0.04,1.0)$ & 0.072 \\
\hline
\end{tabular}



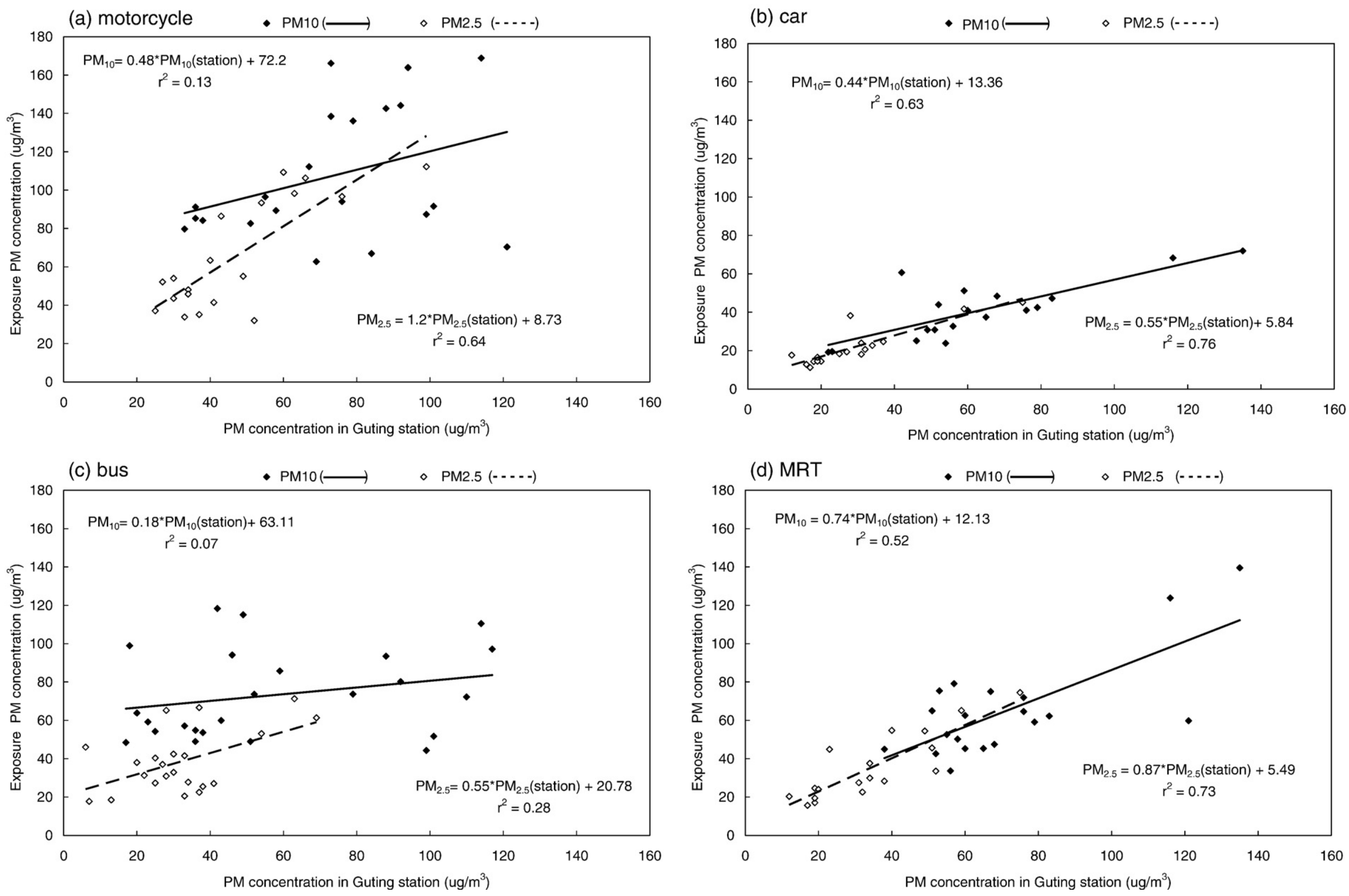

Fig. 1-Regression of commuter's whole-trip PM exposures by fixed-site air monitoring data for four commuting modes in Taipei, Taiwan, 2005. 


\section{Discussion}

Fine/coarse $\left(\mathrm{PM}_{2.5} / \mathrm{PM}_{10}\right)$ ratios of four commuting modes, $0.53-0.60$, were found to be similar to the ratios measured in the fixed site of this study (0.53) and one previous study (0.57) in Taipei (Li and Lin, 2002). $\mathrm{PM}_{2.5}$ usually accounted for more than $50 \%$ of $\mathrm{PM}_{10}$ in metropolitan areas (Chow et al., 1994). Fine particles are dominated by exhaust pipe emissions, while coarse particles consist mostly of crustal materials and usually are related to the traffic-induced abrasion and resuspension process (Vallius et al., 2000). $\mathrm{PM}_{2.5} / \mathrm{PM}_{10}$ ratio at around 0.6 shows that it is strongly influenced by mechanically produced particles (Gehrig and Buchmann, 2003).

Submicron/coarse $\left(\mathrm{PM}_{1.0} / \mathrm{PM}_{10}\right)$ ratios of all modes in our study (0.39-0.45) also fall in the same range (0.22 to 0.60$)$ from the results in Li and Lin's (2002) study. The submicron/coarse ratios in our study results were higher (0.39-0.45), compared with the study results in Phoenix (0.18). Higher $\mathrm{PM}_{1.0} / \mathrm{PM}_{10}$ ratios can reflect more mobile source combustion emissions in urban environment. Therefore, it represents more combustion source emissions in Taipei whereas the measurements in Phoenix may have been influenced by fine sand from the surrounding deserts. The consistently stable $\mathrm{PM}_{1.0} / \mathrm{PM}_{10}$ and $\mathrm{PM}_{2.5} / \mathrm{PM}_{10}$ ratios among all modes imply that road traffic generally provides the major source of ambient particulate pollution (Han and Naeher, 2006).

The lowest fine/coarse and submicron/coarse ratios were found in car mode. The filter in the air-conditioning system is supposed to be capable of removing the larger portion of $\mathrm{PM}_{10}$ (Chan et al., 2002a). Another study reported that the car's airconditioning system can remove between 40 and $75 \%$ of the largest PM (Ptak and Fallon, 1994). However, the low $\mathrm{PM}_{2.5}$ to $\mathrm{PM}_{10}$ ratios found in car may be affected by two reasons. The car's ventilation system was less efficient than expected to remove the larger particles between 2.5 and $10 \mu \mathrm{m}$. In addition, the re-circulation mode of the air-conditioning system might have caused the re-suspension of the coarse dust in the car.

We believe that the physical distance between commuters and traffic-related emission sources, such as tailpipe emissions and re-suspended road dust, may explain why motorcycle and bus commuters had higher PM exposures than car and MRT commuters. Motorcyclists are very close to vehicle tailpipes, as they are often surrounded by cars, buses and other motorcycles when on the road. Bus commuters are potentially exposed to $\mathrm{PM}_{2.5}$ and $\mathrm{PM}_{1.0}$ emitted from vehicles passing by while they are waiting at roadside bus stops. Resuspended dust containing brake and steel wears on the road is another source of their PM exposures, especially $\mathrm{PM}_{10}$ and $\mathrm{PM}_{2.5}$ (Riediker et al., 2004b).

$\mathrm{PM}_{10}, \mathrm{PM}_{2.5}$, and $\mathrm{PM}_{1.0}$ concentrations were elevated when motorcyclists idled at traffic lights or were stuck in traffic jams. Chan et al. had reported that the peaks of $\mathrm{PM}_{10}$ levels were usually observed in the stop-and-go pattern for non-airconditioned vehicles (Chan et al., 2002a). Buses usually run and stop more frequently than other vehicles. Our study shows that higher in-vehicle $\mathrm{PM}_{10}$ concentrations were found when the bus doors were opened, which might not only have allowed ambient air pollutants to enter the cabin but also might have caused the re-suspension of sediment particles. As a result, the number of traffic lights and bus stops could also influence PM concentrations.

Our study shows that commuters' PM exposures are significantly influenced by their choice of commuting modes. Significant long traveling time in the outdoor environment is an important factor contributing to whole-trip PM exposures for motorcycle, bus and MRT commuters. This is the reason why motorcycle, bus and MRT commuters had higher exposure than car commuters. Furthermore, MRT had significantly higher average PM concentrations walking outside the vehicle than staying inside the vehicle. Similarly, a study in Hong Kong also reported that relatively low exposure levels inside subway systems could be attributed to the far distance from busy roads or other traffic emissions (Chan et al., 2002b).

Fixed-site monitoring station data have been commonly used to predict personal exposure levels. The reason why motorcycle and bus commuters' exposures to $\mathrm{PM}_{2.5}$ were poorly associated with the fixed-site air monitoring station data in this study might be due to the certain events that occurred during the commutes, such as idling and the bus door opening. Our study results also showed that the $r^{2}$ of $\mathrm{PM}_{2.5}$ between commuters' exposures and concentrations at the fixed-site air monitoring station were better than the $r^{2}$ of $\mathrm{PM}_{10} . \mathrm{PM}_{2.5}$ is more dominating and evenly distributed over larger areas than $\mathrm{PM}_{10}$. Furthermore, the fluctuation of road traffic caused worse $\mathrm{PM}_{10}$ association with the fixed-site station since the site was not directly exposed to road side traffic.

It should also be noted that the fixed-site $\mathrm{PM}_{2.5}$ monitoring data tend to under-estimate the exposures of motorcycle commuters, but over-estimate the exposures of car, bus and MRT commuters. The reason of under-estimation is that motorcyclists are closer to traffic emissions than the fixed-site monitoring station. By contrast, the reason of over-estimation is that car, bus and MRT commuters spend significant amount of their travel time inside vehicles, which usually have lower $\mathrm{PM}_{2.5}$ concentrations than ambient environment. The reason why fixed-site $\mathrm{PM}_{10}$ monitoring concentrations over-estimate the personal exposure concentrations of car and MRT modes is that many breathing environments are not ambient for both car and MRT commuters, who spend significant amount of commuting time either underground or inside vehicles.

\section{Conclusion}

In conclusion, commuter exposures vary significantly among motorcycle, car, bus and MRT. More mode-specific exposure assessment on PM seems to be necessary because it is impossible to extrapolate the concentrations from one mode to another mode. In addition, information about certain events during commutes should be collected. Finally, current fixed-site monitoring station data cannot be readily applied to estimate commuter exposures because they either overestimated or under-estimated the real exposure. Future fixed-site monitoring station data can better estimate commuter exposures by refining either spatial or temporal attributes of monitoring data related to commuter exposures, such as the traffic condition surrounding commuters, the 
changing distance between the fixed-site monitoring station and commuters, and more detailed time resolution of the fixed-site monitoring data.

\section{Acknowledgments}

We thank the volunteers for their assistance in carrying out this field study.

\section{R E F E R E N C E S}

Adams HS, Nieuwenhuijsen MJ, Colvile RN, McMullen MA, Khandelwal P. Fine particle (PM2.5) personal exposure levels in transport microenvironments, London, UK. Sci Total Environ 2001;279:29-44.

Alm S, Jantunen MJ, Vartiainen M. Urban commuter exposure to particle matter and carbon monoxide inside an automobile. J Expo Anal Environ Epidemiol 1999;9:237-44.

Chan CC, Lin SH, Her GR. Student's exposure to volatile organic compounds while commuting by motorcycle and bus in Taipei City. J Air Waste Manage Assoc 1993;43:1231-8.

Chan CC, Lin SH, Her GR. Office worker's exposure to volatile organic compounds while commuting and working in Taipei City. Atmos Environ 1994;28:2351-9.

Chan LY, Lau WL, Lee SC, Chan CY. Commuter exposure to particulate matter in public transportation modes in Hong Kong. Atmos Environ 2002a;36:3363-73.

Chan LY, Lau WL, Zou SC, Cao ZX, Lai SC. Exposure level of carbon monoxide and respirable suspended particulate in public transportation modes while commuting in urban area of Guangzhou, China. Atmos Environ 2002b;36:5831-40.

Chan CC, Chuang KJ, Shiao GM, Lin LY. Personal exposure to submicrometer particles and heart rate variability in human subjects. Environ Health Perspect 2004;112:1063-7.

Chow JC, Watson JG, Fujita EM, Lu Z, Lawson DR, Ashbaugh LL. Temporal and spatial variations of PM2.5 and PM10 aerosol in the Southern California air quality study. Atmos Environ 1994;28:2061-80.

Chuang KJ, Chan CC, Chen NT, Su TC, Lin LY. Effects of particle size fractions on reducing heart rate variability in cardiac and hypertensive patients. Environ Health Perspect 2005;113:1693-7.

Chuang KJ, Chan CC, Su TC, Lee CT, Tang CS. The effect of urban air pollution on inflammation, oxidative stress, coagulation, and autonomic dysfunction in young adults. Am J Respir Crit Care Med 2007;176:370-6.

de Hartog JJ, Hoek G, Peters A, Timonen KL, Ibald-Mulli A, Brunekreef B, et al. Effects of fine and ultrafine particles on cardiorespiratory symptoms in elderly subjects with coronary heart disease: the ULTRA study. Am J Epidemiol 2003;157:613-23.

Dominici F, Peng RD, Bell ML, Pham L, McDermott A, Zeger SL, et al. Fine particulate air pollution and hospital admission for cardiovascular and respiratory diseases. JAMA 2006;295:1127-34.

DOT. Annual report 2006. Transportation of Department, Taipei City Government; 2006.

Gehrig R, Buchmann B. Characterising seasonal variations and spatial distribution of ambient PM10 and PM2.5 concentrations based on long-term Swiss monitoring data. Atmos Environ 2003;37:2571-80.

Gomez-Perales JE, Colvile RN, Fernandez-Bremauntz AA, Gutierrez-Avedoy V, Paramo-Figueroa VH, Blanco-Jimenez S, et al. Bus, minibus, metro inter-comparison of commuters' exposure to air pollution in Mexico City. Atmos Environ 2007;41:890-901.

Gulliver J, Briggs DJ. Personal exposure to particulate air pollution in transport microenvironments. Atmos Environ 2004;38:1-8.

Han X, Naeher LP. A review of traffic-related air pollution exposure assessment studies in the developing world. Environ Int 2006;32:106-20.

Li CS, Lin CH. PM 1/PM 2.5/PM 10 characteristics in the urban atmosphere of Taipei. Aerosol Sci Technol 2002;36:469-73.

Peters A, von Klot S, Heier M, Trentinaglia I, Hormann A, Wichmann HE, et al. Exposure to traffic and the onset of myocardial infarction. N Engl J Med 2004;351:1721-30.

Pope III CA, Dockery DW. Epidemiology of particle effects. In: Holgate ST, Samet JM, Koren HS, Maynard RL, editors. Air pollution and health, London; 1999. p. 673-705.

Pope III CA, Burnett RT, Thurston GD, Thun MJ, Calle EE, Krewski D, et al. Cardiovascular mortality and long-term exposure to particulate air pollution: epidemiological evidence of general pathophysiological pathways of disease. Circulation 2004;109:71-7.

Praml G, Schierl R. Dust exposure in Munich public transportation: a comprehensive 4-year survey in buses and trams. Int Arch Occup Environ Health 2000;73:209-14.

Ptak TJ, Fallon SL. Particulate concentration in automobile passenger compartments. Part Sci Technol 1994;12:313-22.

Riediker M, Cascio WE, Griggs TR, Herbst MC, Bromberg PA, Neas L, et al. Particulate matter exposure in cars is associated with cardiovascular effects in healthy young men. Am J Respir Crit Care Med 2004a;169:934-40.

Riediker M, Devlin RB, Griggs TR, Herbst MC, Bromberg PA, Williams RW, et al. Cardiovascular effects in patrol officers are associated with fine particulate matter from brake wear and engine emissions. Part Fibre Toxicol 2004b;1:2.

Samet JM, Dominici F, Curriero FC, Coursac I, Zeger SL. Fine particulate air pollution and mortality in 20 U.S. cities, 1987-1994. N Engl J Med 2000;343:1742-9.

TEO. Traffic volume investigation. Traffic Engineering Office, Taipei City Government. http://www.bote.taipei.gov.tw/flow. asp. [accessed date] 2008.5.27.

TRTC. Taipei Rapid Transit Corporation annual report, Taipei; 2005.

Utell MJ, Warren J, Sawyer RF. Public health risks from motor vehicle emissions. Annu Rev Public Health 1994;15:157-78.

Vallius MJ, Ruuskanen J, Mirme A, Pekkanen J. Concentrations and estimated soot content of PM1, PM2.5, and PM10 in a subarctic urban atmosphere. Environ Sci Technol 2000;34:1919-25. 